\title{
Is Non Fasting Glucose Challenge test Sensitive Enough to Diagnose Gestational Diabetes Mellitus? \\ ORIGINAL
}

\section{Abstract}

Background: There is a no consensus over the most sensitive and practical approach to diagnose Gestational Diabetes Mellitus (GDM). The standard 75 grams glucose tolerance test (GTT) is widely practiced to diagnose GDM. However, non-fasting 75-gram Glucose Challenge Test (GCT) with the 2-hour cutoff value of $\geq 140 \mathrm{mg} / \mathrm{dL}$ is also recommended by some professional bodies. The aim of this study was to investigate the sensitivity and specificity of GCT when compared to GTT for diagnosing GDM.

Methods: Pregnant women in period of gestation between 2428 weeks were recruited by simple random sampling method. Non fasting $75 \mathrm{~g}$ GCTs were performed in all followed by fasting $75 \mathrm{~g}$ GTTs within a week time. International Association of the Diabetes and Pregnancy Study Groups (IADPSG) criteria of GTT were used as the reference test to diagnose GDM and 2-hour value of GCT was compared.

Findings: According to IADPSG criteria, 21.5\% (59/274) of pregnant women had GDM, in compared to $13.1 \%$ (36/274) detected by GCT. Sensitivity and specificity of GCT were $40.6 \%$ and $94.4 \%$ respectively. The area under the ROC curve for the ability of 2-hour value of GCT to predict GDM detected by GTT was 0.758 (SE 0.039). According to GTT values, FBS $\geq 92 \mathrm{mg} / \mathrm{dL}$ alone recognized $11.7 \%$ (32/274) of study sample as having GDM. Additional 9.1\% (25/274) and 0.7\% (2/274) of GDM cases were detected with 1 -hour value $\geq 180 \mathrm{mg} / \mathrm{dL}$ and 2 -hour hour value $\geq 153$ respectively.

Conclusion: GCT with 2-hour cutoff value $\geq 140 \mathrm{mg} / \mathrm{dL}$ is not sensitive enough to diagnose GDM recognized by GTT.
Meththananda Herath', Thilak Priyantha

Weerarathna ${ }^{1}$, Dilini Umesha ${ }^{1}$

1 Department of Medicine, Faculty of Medicine, University of Ruhuna, Galle, Sri Lanka.

Contact information:

\section{Meththananda Herath.}

巨" herathtp@gmail.com

” hmmherath@med.ruh.ac.lk

Keywords

Gestational diabetes mellitus (GDM), glucose tolerance test (GTT), Glucose challenge test (GCT) 


\section{Background}

Gestational diabetes mellitus (GDM) is defined as any degree of glucose intolerance with onset or first recognition during pregnancy and it is associated with increased risk of several adverse perinatal and maternal outcomes [1, 2]. Adverse perinatal outcomes include neonatal hypoglycemia, macrosomia which resulting in an increased risk for shoulder dystocia, and the need for neonatal intensive care [3]. Maternal complications of GDM include increased risk of caesarean delivery and pre-eclampsia. Furthermore, women with GDM have up to 60\% risk of developing type 2 diabetes mellitus (T2DM) within 5-15 years of delivery, and it has been suggested that children prenatally exposed to a diabetic milieu have an increased risk for the development of T2DM later in life $[3,4]$. There are several studies showing a significant reduction of those adverse outcomes, if promt \& proper interventions were taken for early diagnosis and to maintain satisfactory control of hyperglycaemia in pregnancy [1, 3]. The landmark study of Hyperglycemia and Adverse Pregnancy Outcome (HAPO) as well as many other studies including the Australian Carbohydrate Intolerance Study in Pregnant Women (ACHOIS) trial had shown maternal hyperglycemia less severe than that used to define overt diabetes was related to clinically important perinatal disorders or problems and that their effects can be reduced by means of treatment [5] [6]. Therefore, the methods used in the diagnosis of GDM should have higher sensitivity to detect even milder cases of GDM.

There is a lack of international consistency with regard to the most sensitive and practical approach to diagnose GDM. While a 75-gram glucose tolerance test (GTT) is commonly employed, glucose challenge test (GCT) with different cutoff values is also widely used throughout the world.

Based on the result of HAPO study, a one-step approach using a 75-g 2-h GTT with new diagnostic criteria has been recommended by International Association of the Diabetes and Pregnancy Study
Groups (IADPSG) [6] and these new criteria have been adopted by several societies, including the American Diabetes Association and the Endocrine Societies $[3,7]$. Other methods used in GDM diagnosis include two step method with combination of GCT and GTT. In this method, GCT is performed in all pregnant women and GTT only for those with positive GCT. Even though this method is widely accepted as the best method, complexity of the procedure is a limiting factor. An alternative method has been proposed by the World Health Organization (WHO) using a 2-h $75 \mathrm{~g}$ GTT, with a threshold plasma glucose concentration of greater than $140 \mathrm{mg} / \mathrm{dL}$ or $7.8 \mathrm{mmol} / \mathrm{L}$ at $120 \mathrm{~min}$ [7]. A number of studies have documented that the treatment of gestational diabetes as defined by WHO criterion reduced serious perinatal morbidity and also improved the woman's health-related quality of life [8]. Diabetes in Pregnancy Study Group India (DIPSI) diagnostic criterion of 2-h PG $\geq 7.8 \mathrm{mmol} / \mathrm{L}$ with $75 \mathrm{~g}$ oral glucose load is a modified version of $\mathrm{WHO}$, in that the $\mathrm{WHO}$ procedure requires women to be in the fasting state, whereas DIPSI procedure is performed in the fasting/nonfasting state irrespective of the last meal timing. Several studies conducted in India have shown it to be effective $[8,9]$.

Sri Lankan College of Obstetricians \& Gynecologists (SCOG) recommendation on GDM screening and diagnosis is similar to DIPSI and include 75 -gram GCT with cutoff value of $140 \mathrm{mg} /$ $\mathrm{dL}$ irrespective of fasting state [10]. Even though there are advantages such as simplicity and easy to perform as it doesn't require pregnant women to be in fasting, this method has not been validated with gold standard for local population. Hence, this prospective study was undertaken to ascertain the validity of GCT with cutoff value of $7.8 \mathrm{mmol} / \mathrm{L}(140 \mathrm{mg} / \mathrm{dL})$ to diagnose GDM in pregnant women in Sri Lanka. 


\section{Method}

\section{Study design}

This study was conducted as a clinic based cross sectional study in a Tertiary Hospital, in Sri lanka. The study was commenced after the approval of the institutional ethics committee, Faculty of Medicine, Galle, Sri Lanka. The minimum sample size required for the study was 139 pregnant women and was calculated based on the estimated prevalence of GDM in Sri Lanka as $10 \%$ with an absolute precision of $5 \%$ in an infinite population. However, the prevalence of GDM is reported to be as high as $22 \%$ with the new diagnostic criteria in a previous single center study in Sri Lanka [11]. Therefore, 296 pregnant women in 24 to 28 weeks of gestation were recruited by simple random sampling method.

All women who consented for the study were subjected to non-fasting 75-gram GCT on the day of recruitment. All of them were invited for the standard 75-gram oral glucose tolerance test (GTT) within a week of recruitment. GTTs were performed after an overnight fast of at least 8 hours and not exceeding 14 hours, and following at least 3 days of unrestricted carbohydrates ( $>150 \mathrm{~g}$ per day) and exercise as per WHO guidelines. Two medically qualified investigators collected data using an interviewer administered questionnaire. The details including age, height, weight, history of diabetes in the family, history of GDM in previous pregnancy, history of previous delivery of large babies, socioeconomic status were obtained using this questionnaire. Participant provided data were confirmed using pregnancy records, previous medical records and hospital records. The body mass index (BMI) of the subjects was calculated using the height and weight. Blood pressures of all the women were recorded. Collection of blood sample was carried out by qualified medical laboratory technicians using standard protocols. All laboratory tests were quality controlled and abnormal results were repeated and confirmed. Plasma glucose measurements were carried out with an automated analyser using the glucose oxidase enzymatic calorimetric assay.

GDM was diagnosed according to standard IADPSG (international Association of the Diabetes and Pregnancy Study Groups) criteria and the diagnosis is made when any of the following three $75 \mathrm{~g}$ 2 hour OGTT thresholds are met or exceeded: Fasting $92 \mathrm{mg} / \mathrm{dL}$, one hour $\geq 180 \mathrm{mg} / \mathrm{dL}$, two hours $\geq 153 \mathrm{mg} / \mathrm{dL}$.

\section{Statistical analysis}

To compare the mean values between the groups independent t-test was used and for proportions, Chi-square test was employed. A receiver operating characteristics (ROC) curve was constructed to test the ability of the 2-hour value of GCT to identify patients with a diagnosis of GDM and to determine the best cutoff value in predicting a GDM diagnosis in our population. P-value $<0.05$ was considered statistically significant. Data analysis was done using statistical package for social science (SPSS) version 20.

\section{Ethical considerations}

Ethical clearance was obtained from ethical review committee of Faculty of Medicine, University of Ruhuna. A written consent was obtained from all pregnant women after detailed written and verbal explanation about the study. Pregnant women found to have GDM were referred to antenatal clinic for treatment and follow up.

\section{Results}

Of the total of 296 women recruited, 15 didn't come for GTT and 07 could not complete the test due to nausea and vomiting. Table 1 shows the baseline characteristics of the 274 women who completed the study. On average, pregnant women were relatively old with mean age of $31.4 \pm 6.7$ years and of average pre-conception BMI $\left(21.7 \pm 4.6 \mathrm{~kg} / \mathrm{m}^{2}\right)$. The differences of the baseline characteristics between 
Table 1. Baseline characteristics between subjects with and without GDM.

\begin{tabular}{|c|c|c|c|c|c|}
\hline \multirow{3}{*}{ Age in years } & & \multirow{2}{*}{$\begin{array}{c}\mathrm{GCT} \geq 140 \\
2\end{array}$} & \multirow{2}{*}{$\begin{array}{c}\mathrm{GCT}<140 \\
11\end{array}$} & \multirow{2}{*}{$\begin{array}{c}\text { with } \mathrm{GDM}^{*} \\
2\end{array}$} & \multirow{2}{*}{$\begin{array}{c}\text { without GDM* } \\
\qquad 11\end{array}$} \\
\hline & $<20$ & & & & \\
\hline & $20-30$ & 9 & 77 & 8 & 78 \\
\hline & $>30$ & 24 & 151 & 49 & 126 \\
\hline \multirow[t]{3}{*}{ Parity } & 1 & 11 & 72 & 12 & 71 \\
\hline & 2 & 8 & 69 & 18 & 59 \\
\hline & $\geq 3$ & 16 & 98 & 29 & 85 \\
\hline POG $^{1}$ & & $26.8+/-3.9$ & $25.9+/-4.7$ & $25.5+/-4.7$ & $26.1+/-4.4$ \\
\hline \multirow[t]{4}{*}{ BMI } & $<18$ & 4 & 47 & 8 & 43 \\
\hline & $18-24.9$ & 20 & 149 & 35 & 134 \\
\hline & $25-29.9$ & 10 & 35 & 15 & 30 \\
\hline & $>30$ & 1 & 8 & 1 & 8 \\
\hline \multicolumn{2}{|c|}{ Past history of GDM } & 3 & 6 & 4 & 5 \\
\hline \multicolumn{2}{|c|}{ Family history of GDM } & 17 & 66 & 23 & 60 \\
\hline \multicolumn{2}{|c|}{ Past history of macrosomia } & 6 & 28 & 8 & 26 \\
\hline
\end{tabular}

subjects with and without GDM (based on IADPSG criteria) and GCT $\geq 140$ and $<140$ were shown in table 1.

Being overweight according to pre-conception BMI (39.3\%) and age over 35 years (39.6\%) were the two most frequently detected risk factors for GDM among the participants in this study. Past history of GDM was reported in 3.3\% and 30.5\% had a first degree relative with diabetes mellitus. Prevalence of the risk factors for GDM within the study population is shown in Table 2 .

According to IADPSG criteria of the 75-gram GTT, $21.5 \%(59 / 274)$ subjects in the sample were diagnosed to have GDM; however, only 13.1\% (36/274) were detected to have GDM with GCT using 2-hour cutoff value $\geq 140 \mathrm{mg} / \mathrm{dl}$. Out of the 36 cases detected by 2 -hour value $\geq 140 \mathrm{mg} / \mathrm{dl}$, 12 women were found to have normal GTT (false positive). Thus, only 24 cases of GDM were diagnosed by GCT with 2-hour value of $\geq 140 \mathrm{mg} / \mathrm{dL}$, giving the sensitivity of $40.6 \%$ and specificity of $94.4 \%$. Close to $60 \%$ (35/59) of patients with true GDM were missed with GCT.
Table 2. Prevalence of risk factors in the study population.

\begin{tabular}{|c|c|c|}
\hline Risk factor & $\mathbf{N}$ & $\%$ \\
\hline Past history of GDM & 09 & 3.3 \\
\hline Maternal age $\geq 35$ years & 108 & 39.6 \\
\hline Pre conception BMI $\geq 23$ kg/m2 & 105 & 39.3 \\
\hline $\begin{array}{l}\text { Bad obstetric history- miscarriages, } \\
\text { still births, IUD etc.) }\end{array}$ & 65 & 23.8 \\
\hline Delivering large babies (>3.45kg) & 34 & 12.4 \\
\hline $\begin{array}{l}\text { History of T2DM/GDM among first } \\
\text { degree relatives }\end{array}$ & 83 & 30.5 \\
\hline \multicolumn{3}{|c|}{$\begin{array}{l}\text { GDM -Gestational Diabetes Mellitus, BMI- Body Mass } \\
\text { Index, IUD- Intra Uterine Death, T2DM-type } 2 \text { diabetes } \\
\text { mellitus. }\end{array}$} \\
\hline
\end{tabular}

When the non-fasting 2-hour cutoff value of GCT is increased to $\geq 152 \mathrm{mg} / \mathrm{dL}$ (the cutoff value used in IADPSG criteria), the detection rate of GDM dropped to $5.8 \%$ (16/274). Furthermore, out of three glucose test of GTT, 1-hour value has the highest sensitivity in detecting GDM followed by FBS (Table 3 \& figure 1). $\mathrm{FBS} \geq 92 \mathrm{mg} / \mathrm{dL}$ recognized $11.6 \%$ (32/274) of study sample as having GDM. Additional of $9.1 \%(25 / 274)$ and $0.7 \%(2 / 274)$ of GDM cases 
Table 3. Comparison of GCT with GTT using IADPSG criteria in diagnosing GDM.

\begin{tabular}{|l|c|c|c|}
\multirow{2}{*}{$\mathbf{G C T} \geq \mathbf{1 4 0} \mathbf{~ m g / d L}$} & \multicolumn{2}{|c|}{$\begin{array}{c}\text { GTT using IADPSG criteria } \\
\text { as gold standard }\end{array}$} & \multirow{2}{*}{ Total } \\
\cline { 2 - 3 } & Positive & Negative & \\
\cline { 1 - 3 } Positive & 24 & 12 & 36 \\
\hline Negative & 35 & 203 & 238 \\
\hline Total & 59 & 215 & 274 \\
\hline
\end{tabular}

GTT-Glucose tolerance test, GCT -Glucose Challenge Test, GDM -Gestational Diabetes Mellitus, IADPSG- International Association of the Diabetes and Pregnancy Study Groups.

Table 4. Number of patients with GDM diagnosed by FBS, $1^{\text {st }}$ hour value and $2^{\text {nd }}$ hour value of GTT.

\begin{tabular}{l|c|c|c|}
\hline & GDM & No GDM & sensitivity \\
\hline FBS* & 32 & 242 & $11.6 \%$ \\
\hline 1st hour value* & 37 & 237 & $13.5 \%$ \\
\hline 2nd hour value* & 16 & 258 & $5.8 \%$ \\
\hline With all 03* & 59 & 215 & $21.5 \%$ \\
\hline *Based on IADPSG (International Association of the \\
Diabetes and Pregnancy Study Groups) criteria.
\end{tabular}

were detected with 1-hour value $\geq 180 \mathrm{mg} / \mathrm{dL}$ and 2-hour hour value $\geq 153$ respectively.

The area under the ROC curve for the ability of 2-hour value of GCT to predict altered FBS and 1sthour value of GTT was 0.758 (SE 0.039) (Fig. 2). The best cutoff point of 2-hour value to predict abnormal FBS and 1st-hour values occurred at $120 \mathrm{mg} /$ $\mathrm{dL}$ (sensitivity of $64.9 \%$, the specificity $76.5 \%$ ) (Fig. 2). If the cutoff 2-hour value of GCT is increased to $140 \mathrm{mg} / \mathrm{dL}$, sensitivity dropped $37 \%$ and specificity increased to $96 \%$ and this is a clear indication that GCT with cutoff 2-hour value of 140 is not sensitive enough to diagnose GDM in compared to gold standard GTT (Fig 2).

The distribution of 2-hour glucose of GCT in women with GDM $(n=59)$ and without GDM $(n=215)$ is shown in Figure 3. Of note, there was considerable overlap in the distribution of 2-hour value between these two patient populations. This probably indicates that there was no clear thres- hold level of 2-hour glucose that can be used to identify GDM.

Figure 1: Number of patients with GDM diagnosed by FBS (fasting blood glucose), $1^{\text {st }} \mathrm{H}$ (15t hour value of GTT, $2^{\text {nd }} H\left(2^{\text {nd }}\right.$ hour value of GTT) based on IADPSG criteria.

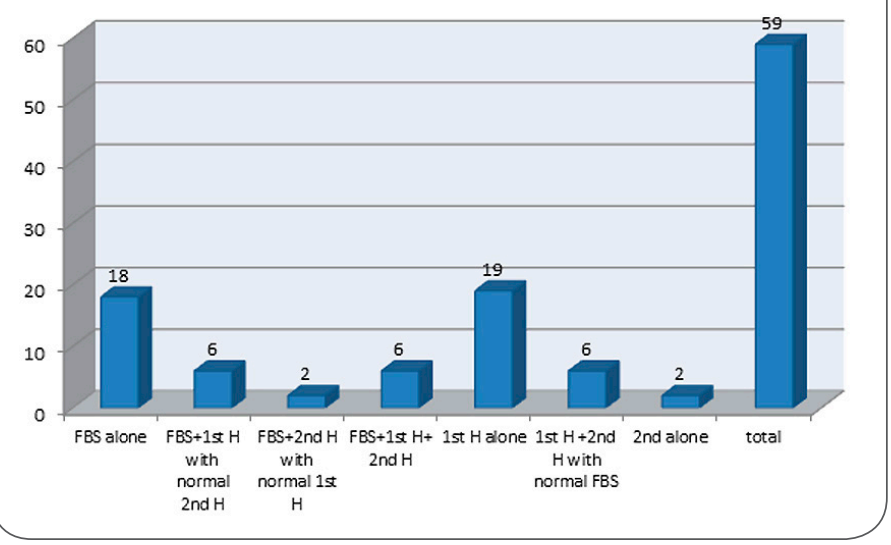

Figure 2: ROC curve of 2-hour value to predict abnormal FBS and 1-hour value.

ROC Curve

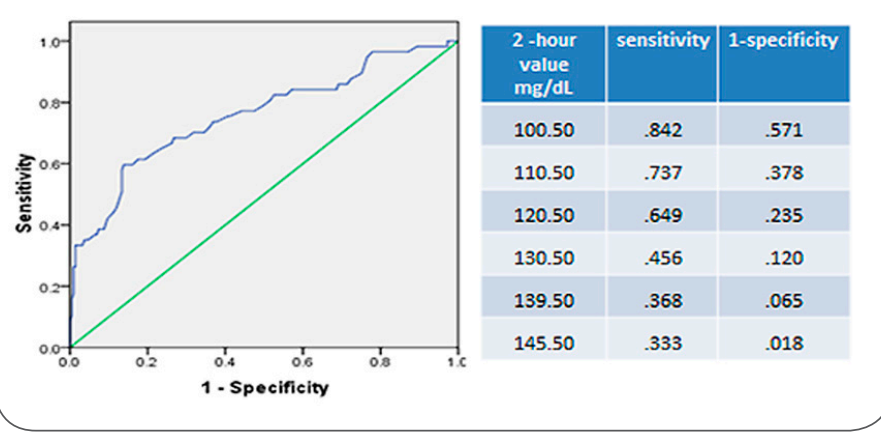

Figure 3: Histogram showing the distribution of 2-hour glucose level of GCT in women with GDM and without GDM.

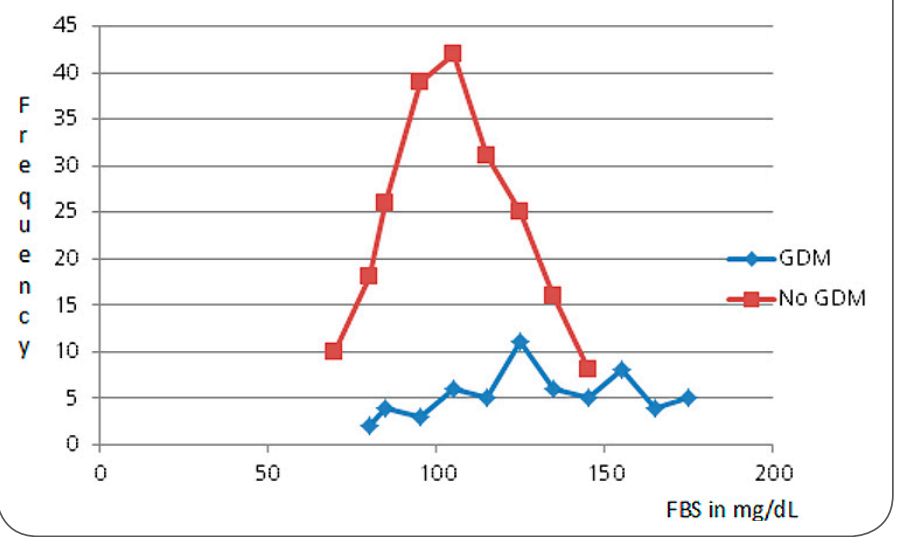




\section{Discussion}

Number of studies have shown the value of fasting Glucose Challenge Test (GCT) with a cutoff value of $140 \mathrm{mg} / \mathrm{dl}$ in diagnosing GDM [1, 8, 12, 13]. Professional organizations including Diabetes in Pregnancy Study Group of India (DIPSI) and Sri Lankan College of Obstetricians \& Gynecologists (SCOG) have recommended non fasting GCT to diagnose GDM based studies carried out in India $[9,10,14]$. However, in these studies GCT was not compared with standard GTT and the cutoff value was justified on the basis of equal prevalence macrosomia in GDM group and non GDM group. Equal prevalence is thought to be due to appropriate recognition and treatment of GDM cases in these studies. However, prevalence of macrosomia as the surrogate marker to diagnose GDM is not accurate as many factors including success of the treatment can confound the prevalence of macrosomia. There are other studies showing poor sensitivity of GCT in diagnosing GDM $[15,16]$. In a recent study done in Indian ethnicity had shown very low sensitivity of non- fasting GCT when compared to IADPSG criteria (sensitivity $22.6 \%$, specificity $97.8 \%$ ) [17]. Other studies done in South Asian ethnicity as well as in Caucasians too had revealed poor sensitivity of 50 -gram and 75-gram GCT [15, 18, 19].

Results of our study clearly indicated that the non-fasting GCT had a poor sensitivity (40.6\%) when compared to GTT with IAPDSG criteria. Even though sensitivity of GCT in our study is slightly better when compared to the study conducted by Mohan $V$ et al, the sensitivity of $40 \%$ is far below the acceptable limit to use as a screening tool. GCT would not only miss around $60 \%$ of cases, but it would falsely diagnose $33 \%$ cases as having GDM (false positive rate of $33 \%, 12 / 36$ ). All this $33 \%$ of cases detected as GDM will unnecessarily undergo more investigations and intervention including dietary modification. Magnitude of recommending and using wrong test can be un- derstood if we look at the prevalence of GDM. A previous study conducted in a tertiary care center showed alarmingly high prevalence of GDM (22\%) among pregnant women in Sri Lanka. If GCT is used in a Tertiary care Hospital which has delivery rate of 1000/per month it would miss around 132 GDM cases per month.

The main reason for recommending GCT over GTT is the simplicity of non-fasting GCT. Advocators of non-fasting GCT believe that GTT is too complex to perform in the antenatal clinic setting and also would result in significant low turnover as it require pregnant women to be overnight fast. However our study as well as previous studies had shown that pregnant women had good compliance with GTT when motivated [17].

Our study has clearly shown 1-hour value of GTT was better target than the 2 hour value. Similar finding was observed in the HAPO study and shown that when adjusted for confounders, the 1-hour plasma glucose level remained a better predictor of primary outcome. In HAPO study FBS $\geq 92 \mathrm{mg} /$ $\mathrm{dl}$ alone recognized $8.3 \%$ of the HAPO population as having GDM. Adding the 1 hour threshold of $180 \mathrm{mg} / \mathrm{dl}$ identified an additional $5.7 \%$ of the population who did not have an elevated fasting value and adding the 2 hour threshold of $153 \mathrm{mg} /$ $\mathrm{dl}$ identified an additional $2.1 \%$ of the population [20]. The finding of HAPO study had indicated that targeting 2-hour value after glucose load was not the best option. Our findings were also similar to the finding of HAPO study. In our study FBS $\geq 92$ $\mathrm{mg} / \mathrm{dL}$ recognized $11.6 \%$ (32/274) of study sample as having GDM. Additional of 9.1\% (25/274) and $0.7 \%(2 / 274)$ of GDM cases were detected with 1-hour value $\geq 180 \mathrm{mg} / \mathrm{dL}$ and 2-hour hour value $\geq 153$ respectively.

\section{Conclusions}

The fasting GCT with cutoff value of $\geq 140 \mathrm{mg} / \mathrm{dL}$ lacks adequate sensitivity to diagnose GDM. We 
recommend fasting GTT to diagnose GDM in all pregnant women even though it needs fasting state and three blood tests. If performing full GTT is practically difficult, FBS together with 1-hour plasma glucose after 75 gram glucose load is a good alternative.

\section{Acknowledgements}

$\mathrm{MH}$ was supported by a grant from TURIS project of University of Ruhuna (TP/2011/M/04). We express our gratitude to TURIS project for the financial assistance. A special word of thank is extended to all participants of this study, K. M Kumuduni de Silva and K S M Weerarathna for laboratory assistance, and Dr SP Mohotti, Dr CM De Silva and Dr L Fonseka of Diabetic Research Unit for their assistance in conducting this study.

\section{Competing interests}

The authors declare that they have no competing interests.

\section{Authors' contributions}

$\mathrm{MH}$ designed the study, supervised and performed the study, analyzed data and wrote the article, TPW analyzed data and critically reviewed the manuscript, DU collected the data and reviewed the manuscript.

\section{Authors' information}

$\mathrm{MH}$ is a senior lecturer, Faculty of Medicine, University of Ruhuna and honorary consultant physician University Medical Unit, Teaching Hospital, Galle, Sri Lanka. TPW is a professor in medicine, Faculty of Medicine, University of Ruhuna and honorary consultant physician University Medical Unit, Teaching Hospital, Galle, Sri Lanka, DU is a research assistant, Department of Medicine, Faculty of Medicine, University of Ruhuna

\section{References}

1. Metzger BE, Coustan DR: Summary and recommendations of the Fourth International Workshop-Conference on Gestational Diabetes Mellitus. The Organizing Committee. Diabetes care 1998, 21 Suppl 2: B161-167.

2. Holt RI: The Hyperglycemia and Adverse Pregnancy Outcomes trial: answers but still more questions about the management of gestational diabetes. Diabetic medicine: a journal of the British Diabetic Association 2008, 25(9): 1013-1014.

3. Group HSCR: Hyperglycemia and Adverse Pregnancy Outcome (HAPO) Study: associations with neonatal anthropometrics. Diabetes 2009, 58(2): 453-459.

4. Maresh M: Screening for gestational diabetes mellitus. Seminars in fetal \& neonatal medicine 2005, 10(4): 317-323.

5. Group HSCR, Metzger BE, Lowe LP, Dyer AR, Trimble ER, Chaovarindr U, Coustan DR, Hadden DR, McCance DR, Hod $M$ et al: Hyperglycemia and adverse pregnancy outcomes. The New England journal of medicine 2008, 358(19): 1991-2002.

6. Crowther CA, Hiller JE, Moss JR, McPhee AJ, Jeffries WS, Robinson JS, Australian Carbohydrate Intolerance Study in Pregnant Women Trial G: Effect of treatment of gestational diabetes mellitus on pregnancy outcomes. The New England journal of medicine 2005, 352(24): 2477-2486.

7. Alberti KG, Zimmet PZ: Definition, diagnosis and classification of diabetes mellitus and its complications. Part 1: diagnosis and classification of diabetes mellitus provisional report of a WHO consultation. Diabetic medicine: a journal of the British Diabetic Association 1998, 15(7): 539-553.

8. Balaji V, Balaji M, Anjalakshi C, Cynthia A, Arthi T, Seshiah $\mathrm{V}$ : Diagnosis of gestational diabetes mellitus in Asian-Indian women. Indian journal of endocrinology and metabolism 2011, 15(3): 187-190.

9. Seshiah V, Sahay BK, Das AK, Shah S, Banerjee S, Rao PV, Ammini A, Balaji V, Gupta S, Divakar $H$ et al: Gestational diabetes mellitus--Indian guidelines. Journal of the Indian Medical Association 2009, 107(11): 799-802, 804-796.

10. Goonewardene M, Dias T: Antenatal care: paradigm changes over the years. The Ceylon medical journal 2013, 58(2): 47-50.

11. Herath HMM MS, De Silva CM, Weerarathna TP: Universal versus selective screening of gestational diabetes mellitus (GDM) in a Sri Lankan population. http://ccplk/wp-content/ uploads/2013/01/CCP-AAS-Abstract-book-20131pdf 2013.

12. Virally $M$, Laloi-Michelin M: Methods for the screening and diagnosis of gestational diabetes mellitus between 24 and 28 weeks of pregnancy. Diabetes \& metabolism 2010, 36(6 Pt 2): 549-565.

13. Sharma K, Wahi P, Gupta A, Jandial K, Bhagat R, Gupta R, Gupta $S$, Singh J: Single glucose challenge test procedure for diagnosis of gestational diabetes mellitus: a Jammu cohort study. The Journal of the Association of Physicians of India 2013, 61(8): 558-559 
14. Anjalakshi C, Balaji V, Balaji MS, Ashalata S, Suganthi S, Arthi T, Thamizharasi M, Seshiah V: A single test procedure to diagnose gestational diabetes mellitus. Acta diabetologica 2009, 46(1): 51-54.

15. van Leeuwen $M$, Louwerse $M D$, Opmeer BC, Limpens J, Serlie MJ, Reitsma JB, Mol BW: Glucose challenge test for detecting gestational diabetes mellitus: a systematic review. BJOG: an international journal of obstetrics and gynaecology 2012, 119(4): 393-401.

16. Crete JE, Anasti JN: Diagnosis of gestational diabetes mellitus: can we avoid the glucose challenge test? Journal of the American Association of Nurse Practitioners 2013, 25(6): 329-333.

17. Mohan V, Mahalakshmi MM, Bhavadharini B, Maheswari K, Kalaiyarasi G, Anjana RM, Uma R, Usha S, Deepa M, Unnikrishnan $\mathrm{R}$ et al: Comparison of screening for gestational diabetes mellitus by oral glucose tolerance tests done in the non-fasting (random) and fasting states. Acta diabetologica 2014.

18. Montagnana M, Lippi G, Targher G, Fava C, Guidi GC: Glucose challenge test does not predict gestational diabetes mellitus. Internal medicine 2008, 47(13): 1171-1174.

19. Hansarikit J, Manotaya S: Sensitivity and specificity of modified 100 -g oral glucose tolerance tests for diagnosis of gestational diabetes mellitus. Journal of the Medical Association of Thailand = Chotmaihet thangphaet 2011, 94(5): 540-544.

20. Coustan DR, Lowe LP, Metzger BE, Dyer AR: The Hyperglycemia and Adverse Pregnancy Outcome (HAPO) study: paving the way for new diagnostic criteria for gestational diabetes mellitus. American journal of obstetrics and gynecology 2010, 202(6): 654.e651-656.

\section{Comment on this article:}
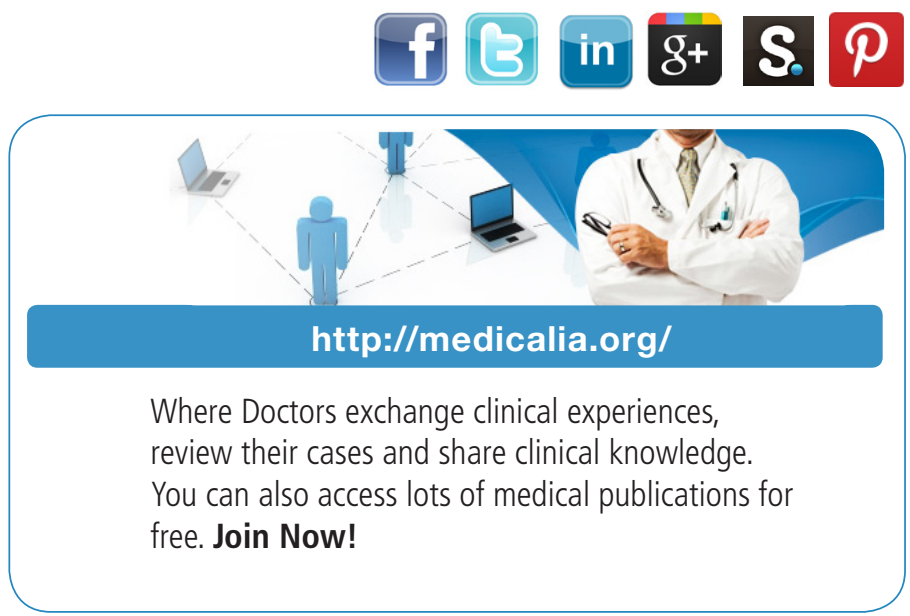

\section{Publish with iMedPub}

\section{http://www.imed.pub}

International Archives of Medicine is an open access journal publishing articles encompassing all aspects of medical science and clinical practice. IAM is considered a megajournal with independent sections on all areas of medicine. IAM is a really international journal with authors and board members from all around the world. The journal is widely indexed and classified Q1 in category Medicine. 